\title{
Gamificação e Educação em Design na Era Digital
}

Richard Perassi Luiz de Sousa;

Stefania Bragagnolo

Resumo: De modo geral, a gamificação é o sistema de aplicação da estrutura e da dinâmica lúdica dos jogos em atividades e processos. A concepção ortodoxa de jogo indica uma atividade voluntária, atribuída ao divertimento e com desígnio próprio. Contudo, historicamente, parte dos jogos foi destinada ao atendimento de outras finalidades. Neste artigo, são apresentadas duas abordagens complementares no âmbito de Design de Jogos, uma pertinente ao campo de Design Comportamental e outra mais próxima ao Design de Produtos e Comunicação, renovado com a tecnologia digital. 0 objetivo deste estudo é indicar a aplicação da gamificação voltada aos aspectos pedagógicoseducativos e nas particularidades de ensino-aprendizagem em cursos de Design. Os conceitos e os argumentos aqui apresentados resultaram de uma pesquisa qualitativa, realizada em duas etapas, sendo uma exploratória e outra bibliográfica. Como resultado, evidencia-se a possibilidade de aplicação da gamificação na educação em Design e nos processos de ensino-aprendizagem dos cursos desta área do conhecimento.

Palavras-chave: Design de Jogos; Gamificação Pedagógica; Cultura Digital 


\section{Introdução}

Apesar das fortes crises sociopolíticas e financeiras do século $\mathrm{XX}$, houve o contínuo progresso tecnológico que, muitas vezes, foi impulsionado no enfrentamento dos conflitos da época. Inclusive, o progresso acentuado resultou na revolução tecno-digital que, em seguida, provocou a superação da cultura industrial, inaugurando e consolidando o domínio da atual cultura digital ou cibercultura (LÉVY, 1999; ANTOUN, 2004).

A associação da tecnologia digital com a produção industrial ampliou, diversificou e liberou as possibilidades criativas na projetação e no desenvolvimento de processos e produtos nas áreas de Design. Isso também repercutiu imediatamente na cultura de mercado, com o uso da tecnologia digital no atendimento de nichos de consumo, incluindo ofertas individualizadas ou em pequena escala, entre outras variáveis.

Ainda assim as mudanças tecnológicas, culturais e mercadológicas já consolidadas questionam as estratégias e as ações didático-pedagógicas tradicionais nos cursos de Design em diferentes níveis. Porém, como ocorre nos processos gerais de ensino-aprendizagem e educação, isso indica a necessidade e a oportunidade de revisão crítica, com substituição ou aprimoramento daquilo que, anteriormente, serviu para atender aos parâmetros didático-pedagógicos na cultura industrial. Isso é especificamente justificado porque, na atual sociedade digital do conhecimento, a rigidez da cultura industrial foi amplamente liberada, dinamizada e em grande parte ultrapassada, principalmente com a popularização do acesso à tecnologia-informática e à comunicação em rede online.

A atividade da cultura industrial solicitava a educação centrada na formalidade porque, na época, a interação com as máquinas necessitava que os profissionais e as pessoas em geral aprendessem e adotassem normas e procedimentos normalizados e metrificados.

No entanto, embora houvesse uma ampla demanda por criatividade, o encaminhamento necessário das propostas didático-pedagógicas visava condicionar as intenções e as ideias ao conjunto de normas requeridas para sua realização. Inclusive, para atender à necessidade de resumir intenções e ideias a formas e cores básicas que, coerentemente, pudessem ser percebidas e reproduzidas por máquinas ainda incipientes, como propunha com sucesso a pedagogia bauhausiana (WICK, 1989).

Por sua vez, a dinâmica da cultura digital, atualmente, é baseada em máquinas cujas interfaces são cada vez mais amigáveis, permitindo que, com muita agilidade, sejam realizados procedimentos por tentativa e erro, cujos resultados intermediários ou finais são imediatamente percebidos, considerados, registrados e podem ser recuperados no sistema. Deste modo, a interação humanomáquina é cada vez mais intuitiva e no desenvolvimento de projetos ou produtos digitais, os processos criativos e produtivos são simultâneos. Nesses casos, ao terminar o processo, o produto também é realizado e concluído.

$\mathrm{Ou}$ seja, as interfaces gráfico-digitais assistidas por programas computacionais permitem a livre criação por parte do usuário e ao mesmo tempo, os resultados gráficos são metrificados, formalizados ou codificados e registrados pelo sistema tecnológico-digital.

A tecnologia digital precisa cada vez menos que o usuário formalize seus conhecimentos e procedimentos para o desenvolvimento de projetos e produtos gráficos, entre outros. Ao contrário disso, dominando um conjunto básico e reduzido de conhecimentos e procedimentos, os usuários dispõem de grande diversidade de recursos para realizarem ações que manifestem suas intenções e ideias. Até mesmo, a formalização, o registro, a recuperação e a comunicação do que foi produzido são realizados pelo sistema tecnológico-digital interligado em rede online.

Além disso, os recursos digitais de busca na rede online ainda permitem pesquisas em diversos repositórios de dados e informações digitais. Portanto, fora as informações internas disponibilizadas pelos softwares já instalados no hardware, também é possível acessar e pesquisar o conteúdo acessível através da rede online.

Em suma, diferente de épocas anteriores, atualmente não é prioritário requerer dos estudantes a memorização de grande quantidade de informações diversificadas e o restrito atendimento às normas ou métricas de produção. Assim, o estímulo à intuição, à criatividade, à inovação e o domínio dos recursos digitais, o entendimento dos processos de pesquisa e de construção do conhecimento são o que se apresenta mais relevante. 
$\mathrm{Na}$ sua maioria, o que foi indicado na atualidade ainda era necessário em épocas anteriores. Contudo, a ênfase é distinta, porque, antigamente, ressaltavam-se a formalização e a normalização que nos dias de hoje, são priorizadas a intuição e a criatividade, principalmente em função do uso de sistemas digitais normalizadores. A realidade atual propõe a liberação das capacidades intuitivoafetivas e criativo-cognitivas, oferecendo ainda mais oportunidades para o exercício da subjetividade e das habilidades individuais.

Neste contexto, isso justifica a crítica já consensual que é feita ao ensino informativonormativo. A possibilidade de armazenamento digital de conteúdo codificado e o rápido acesso a dados e informações guardados nas memórias das máquinas ou disponíveis através da rede digital online alteraram radicalmente a dinâmica do conhecimento e do desenvolvimento de teorias e produtos. Além de estarem disponíveis no ciberespaço e mesmo sem requerimento prévio, uma ampla e diversificada quantidade de informações é continuamente recebida nas interfaces digitais dos aparatos eletrônicos, como conteúdo que circula nas redes sociais online (CASTELLS, 2013).

O exercício da criatividade e a produção de conhecimento e artefatos por tentativa e erro não são suficientes para a formação de qualidade dos estudantes. Porém, a facilidade e a agilidade para realizar experiências ou prototipagens rápidas de suas intenções e ideias colaboram na construção de mentes inquisidoras e críticas. Por isso, são promovidos recursos e conhecimentos para os estudantes realizarem a consequente organização e aplicação coerente do que foi descoberto ou desenvolvido.

Diante da necessidade construtiva de interação entre criatividade e coerência, neste artigo, são propostos o projeto e a prática de gamificação como recursos lúdicos que privilegiam a expressão da subjetividade, incentiva o uso de intuição e criatividade bem como, considera a formalização de procedimentos e a proposição de limites e regramentos. Aqui, a gamificação é apresentada como:

1. Recurso propício ao incentivo da pesquisa;

2. Exercício de aproveitamento criativo de informações pesquisadas ou recebidas;

3. Oportunidade de desenvolvimento de projetos menos rígidos e mais inovadores.

$\mathrm{O}$ estudo relatado foi baseado em pesquisa qualitativa, realizada basicamente em duas etapas: (1) uma etapa exploratória para a identificação e seleção de fontes e (2) outra etapa bibliográfica com estudo e seleção de conceitos, argumentos e arranjos teóricos. Marconi e Lakatos (2007) assinalam que, na abordagem qualitativa, descreve-se o objeto, analisando-o e interpretando-o de maneira específica e aprofundada, como fenômeno humano ou social.

Com relação à etapa exploratória, Mattar (2005) indica sua prévia realização, para a construção do conhecimento geral do tema pesquisado e a identificação de questões para serem aprofundadas na continuidade do estudo. Por sua vez, Valentim (2005) considera que a etapa bibliográfica deve oferecer a teoria necessária ao exercício de interpretação desenvolvido no estudo qualitativo.

\section{Educação a distância na era tecnológico-digital}

Atualmente, há mais de uma geração de profissionais e estudantes de Design, entre outros, que Prensky (2001) designaria como "nativos digitais", considerando-se aqui os que nasceram a partir dos anos 1990. Entretanto, parte dos professores são "migrantes digitais", sendo composta por nascidos em épocas anteriores à consolidação dos efeitos da revolução digital. Aliás, os diferentes aspectos que influenciaram os estudantes "nativos digitais" e os professores "migrantes digitais" são recorrentemente indicados nas discussões pedagógicas. Logo, as diferenças mais perceptíveis são as que definem as variáveis de sua adaptação ao sistema tecnológico-digital.

Mesmo que, ocorrendo depois da mudança entre os séculos XX e XXI, as duas últimas décadas também constituem o novo milênio. Até agora, o "novo tempo" é marcado pela popularização do acesso aos aparatos digitais conectados em rede online, com destaque ao uso ampliado de smartphones. Sobre isso, Jenkis (2009) considera a convergência digital em progresso um fenômeno proeminente na fluência informativo-interativo-comunicativa porque, entre outras possibilidades, há o relacionamento de diversas plataformas midiáticas, que sustentam diferentes redes sociais online de comunicação digital. 
Em função da crise sanitária de amplitude mundial, por causa da transmissão de Covid-19, vive-se o período de pandemia que assolou o primeiro semestre de 2020 , estendendo-se ao longo do ano e ameaçando persistir no próximo ano. No contexto de isolamento social induzido, os usos dos recursos digitais interligados em rede online estão cada vez mais explorados ao máximo. Sendo assim, tendem a progredir rapidamente, com o avanço da oferta de melhores recursos tecnológicos e até mesmo da ampliação renovada dos modos de uso. Esta situação afetou profundamente as atividades econômicas e sociopolíticas, incluindo o trabalho pedagógico, em todos os seus níveis de ensinoaprendizagem.

A inadaptação dos processos didático-pedagógicos tradicionais já era reconhecida em ações de ensino-aprendizagem ou educação a distância. Todavia, com a necessidade de transferência de toda a educação presencial para o trabalho a distância, isso foi amplamente reconhecido. Por exemplo, nos processos de educação a distância, as relações síncronas e assíncronas costumam ser diametralmente opostas. No que diz respeito a educação presencial, predomina nos participantes a disposição de investirem nas atividades síncronas e presenciais, com seus corpos físicos reunidos no mesmo ambiente material. Desta maneira, a educação a distância, a disposição predominante é o investimento nas atividades assíncronas e geograficamente distanciadas.

O distanciamento físico-social e a mediação técnico-digital reduzem a afetividade e a efetividade das aulas síncronas que, para serem eficientes, devem ser reduzidas no seu tempo de duração. De modo semelhante, deve ser curto o tempo das aulas audiovisuais previamente gravadas que, em seguida, são disponibilizadas aos estudantes. Além disso, o domínio das atividades assíncronas na educação a distância, necessita de incrementos.

Por isso, o uso de jogos ou gamificação é indicado para a motivação, a mobilização e a integração dos estudantes, em função da eficiência no trabalho com o conteúdo, do necessário interesse e da dedicação requisitada no processo de ensino-aprendizagem, principalmente nas ações a distância. A educação em geral, incluindo a oferta didático-pedagógica em "ambientes virtuais de ensino e aprendizagem" (AVEA) ou com o uso de outros recursos digitais a distância, requer o engajamento ativo de professores, estudantes e outros agentes pedagógicos.

Para Montanaro (2018), são necessários planejamentos e ações didático-pedagógicas eficientes visando o engajamento dos estudantes, sendo esse um atributo necessário a todos os participantes dos diversos processos de ensino-aprendizagem, sejam presenciais ou a distância. Há ainda o alerta de que nos processos didático-pedagógicos dos cursos de Arte, Moda e Design, entre outros, o processo de ensino-aprendizagem deve ser parte de um sistema maior de educação para criatividade e inovação, tornando a missão pedagógica mais desafiadora.

\section{Aspectos relevantes de jogos e processos de gamificação}

Se procurar montar uma estrutura simples para a experiência humana, indica-se que a vida ocorre entre três tipos de condicionamentos: (1) a necessidade, (2) o dever e (3) o prazer. Estas condições não são excludentes entre si. Aliás, é possível que haja prazer no suprimento dos anseios e na execução dos afazeres. Destaca-se o prazer usufruído durante o atendimento de necessidades ou cumprimento de deveres. Geralmente, trata-se do prazer decorrente do processo, consciente ou não, de gamificação da experiência. No qual, é prazeroso constituir e enfrentar os desafios da vida como um jogo.

De maneira independente das necessidades ou dos deveres, o jogo constitui uma atividade que se destaca entre as mais prazerosas. Por sua vez, a gamificação requisita o planejamento e o desenvolvimento para a realização lúdica de diversas atividades ou processos que, originalmente, não são jogos. Para Fardo (2013), a gamificação é a inserção da estrutura e da dinâmica de jogo em diversos processos ou atividades.

Diante disso, considera-se que, em si mesmos, os jogos são atividades pessoais ou sociais necessárias, prazerosas e autocentradas, porque dispensam outras finalidades. No entanto, os jogos podem ser planejados e desenvolvidos como mais ou menos sérios (serious-games). Isso geralmente ocorre com a gamificação, quando os princípios dos jogos são aplicados no atendimento de necessidades ou no cumprimento de deveres. Assim, há jogos em que priorizam outras finalidades, 
pessoais e sociais, incluindo as pedagógicas. A propósito, isso indica a inserção de jogos nos processos de ensino-aprendizagem (ISOTANI; BITTENCOURT; ROCHA, 2015).

Sendo assim, existem princípios básicos, estruturantes e gerais, que caracterizam os jogos e são aplicados nos projetos de gamificação, com intuito de constituírem os jogos sérios (seriousgames). Comumente, um jogo é caracterizado por:

A. "Imprevisibilidade", porque não há a prévia garantia dos bons resultados. Todo jogo implica em uma aposta. Existindo jogos em que o sucesso ou o infortúnio dependem totalmente do acaso, caracterizando os "jogos de azar" ou sorte. Mas, em outras situações, isso pode depender de habilidade ou habilidades, intuitivas, cognitivas ou físicas, dos jogadores.

B. "Múltiplas possibilidades", geralmente, pode haver diversos arranjos possíveis para o percurso dos jogadores. Isso é consequência direta da imprevisibilidade característica dos jogos. Às vezes, a multiplicidade de possibilidades prejudica o jogador e, outra vezes, oportuniza o planejamento de estratégias e o desenvolvimento de ações que lhes são favoráveis. Juntamente com a imprevisibilidade, as múltiplas possibilidades incrementam a ludicidade dos jogos e seu potencial de divertimento, porque provocam surpresas agradáveis e desagradáveis ou permitem soluções incomuns.

C. "Limites e regras", porque os jogos são constituídos como realidade autônoma ou simulação mais ou menos estilizada de outras realidades. Entretanto, as realidades são percebidas e identificadas por limites ou dinâmicas próprias. Além de seus próprios limites e regras, os jogos de simulação incluem regras e limites da realidade simulada. Por fim, a ludicidade, caracterizada por imprevisibilidade e diversas possibilidades, também depende de uma estrutura de limites e regras para que possa ocorrer.

Observa-se que as expressões "diversão" e "divertimento" são etimologicamente relacionadas aos termos "diverso", "diversificado" e "divergente". Portanto, imprevisibilidade e diversidade são condições para que os jogos sejam lúdicos ou "divertidos". Em síntese, (A) imprevisibilidade e diversão; (B) múltiplas possibilidades, e (C) limites ou regras estruturam os jogos.

Assim, partindo do esquema estrutural (A, B, C), busca-se desenvolver um suporte para a desempenho lúdico. Considerando que, os jogos são detalhados e complementados com outros aspectos e elementos distintivos de cada tipo de jogo e de cada jogo individualmente:

1. Adversários ou obstáculos a serem superados por um jogador ou grupo de jogadores.

2. Objetivo final e conquistas em etapas ou fases intermediárias;

3. Ações de interatividade (jogabilidade) entre jogadores ou entre esses e sistema lúdico;

4. Detalhamento do sistema de regras, condições de vitória, derrota e, se houver, empate;

5. Detalhamento dos fatores de entretenimento, como imprevisibilidade ou surpresas.

Na literatura do século XX, um dos pioneiros no estudo antropológico e social do conceito e dos tipos de jogos foi Johan Hüizinga (1872-1945) que, resumidamente, considerou o jogo uma atividade voluntária, que ocorre em condições específicas de espaço e tempo, "segundo regras livremente consentidas, mas absolutamente obrigatórias, dotado de um fim em si mesmo, acompanhado de um sentimento de tensão e alegria e de uma consciência de ser diferente da vida cotidiana" (HUIZINGA, 2007, p. 33).

Para Huizinga (2007), o jogo é indicado como atividade com objetivo próprio. Isso diferencia a ideia do "jogo em si mesmo" do processo de gamificação, que busca atender outras finalidades. Desta forma, há outras indicações que são especialmente relevantes na gamificação pedagógica. Por exemplo, deve-se considerar a atividade voluntária, isso requer a motivação dos estudantes para se voluntariarem. Além disso, a atividade de gamificação deve provocar estados de empolgação, alegria e compor realidade diferenciada da vida cotidiana.

\subsection{A gamificação pedagógica nos cursos de Design}

Conforme o descrito anteriormente, de um modo mais amplo, busca-se estabelecer atualmente o isolamento social em função da pandemia de Covid-19. Isso tem impedido os processos pedagógicos presenciais nos espaços materiais e provocado o uso massivo dos recursos tecnológicos e didático- 
pedagógicos de educação a distância. No entanto, independentemente das circunstâncias atuais, foi assinalado que a oferta e o domínio dos recursos tecnológico-digitais interligados em rede online alteraram radicalmente as relações culturais, sociopolíticas e também a aquisição e a produção de conhecimento e o desenvolvimento de processos, projetos e produtos. Enfim, foi considerado ainda que haverá consequências na retomada da prática didático-pedagógica presencial, depois que os recursos digitais de interação e comunicação a distância foram amplamente explorados nas diversas circunstâncias educativas e de ensino-aprendizagem,

Em atenção às possibilidades e às necessidades didático-pedagógicas, presenciais ou a distância, o tema central deste estudo é a gamificação, como recurso interessante e adequado à educação contemporânea. Que permite, o recorte mais específico do estudo considera a gamificação no desenvolvimento dos cursos de Design. A ideia básica é que a gamificação beneficia a prática didático-pedagógica das aulas centradas em atividades criativas, como os de Arte, Moda e Design, entre outras áreas dos saberes que envolvam essas características.

Proposto em 2002, pelo pesquisador britânico Nick Pelling, o termo "gamificação" (gamification) é relativamente recente (SIGNORI; GUIMARÃES, 2016). Por sua vez, a popularização ocorreu a partir de 2010. Mas muito antes disso, os jogos, a emulação e a ludicidade foram vastamente empregadas na educação. Por exemplo, essas práticas foram e ainda são oficialmente adotadas no processo de ensino-aprendizagem jesuítico, de acordo com as orientações prescritas em 1599, no "Plano e Organização de Estudos da Companhia de Jesus" (Ratio atque Institutio Studiorum Societatis Iesu - Ratio Studiorum). Posteriormente, foram publicadas muitas obras que registram os processos ocidentais de educação, com referências específicas e orientações metodológicas recorrentes sobre o uso de jogos e o valor didático-pedagógico do lúdico. Isso inclui autores como Friedrich Fröbel (17821852) e Lev Vygotsky (1896-1934).

A relação entre gamificação e Design, entretanto, é particularmente interessante porque, comumente, essa implica no desenvolvimento de projetos para desenvolver como jogos as atividades e os processos. Mais especificamente, há projetos de gamificação que implicam em criação, projetação e produção de produtos de sinalização e comunicação. No caso, a finalidade é configurar, visualmente ou em linguagem multimídia, os elementos, os parâmetros e o sistema dinâmico que constitui a realidade perceptível-interativa do jogo.

Afinal, pode ser estabelecido um exercício de metalinguagem, sendo adotada a linguagem projetual de Design para configurar o processo de gamificação no estudo e no desenvolvimento de conteúdos e atividades característicos da área de Design. Isso propõe o investimento em Design de Jogos, visando a aplicação e o detalhamento da estrutura lúdica em processos ou atividades didáticopedagógicas de Design.

Em um sentido amplo, a palavra design representa a ideia de planejamento e projetação de maneira ampla, incluindo diversas áreas de conhecimento e atividades. Assim, indica sentidos e significados que ultrapassam os limites do tradicional desenho industrial. Entre outras possibilidades, há duas abordagens complementares sobre a relação entre gamificação, Design de Jogos (game design), educação e ensino-aprendizagem em Design:

1. A primeira enfatiza o planejamento de gamificação ou jogo como um sistema de emulação e recompensas, com processos de planejamento e desenvolvimento para tornar a experiência interessante, excitante e evolvente. Basicamente, isso implica no planejamento da relação entre desafios, atuações e recompensas. Como também envolve um complexo sistema de considerações antropológicas e sociopsicológicas. Que muitas vezes, o sucesso resulta predominantemente de decisões afetivo-intuitivas, assinalando a "arte" de planejar e desenvolver jogos. No entanto tem teorias e práticas formais, para a compreensão lógica e a proposição de recursos teórico-científicos e técnico-metodológicos de desenvolvimento dos jogos (CHOU, 2015), caracterizando assim a ciência e a tecnologia de game design.

2. A outra abordagem enfatiza o projeto e o desenvolvimento de produtos, principalmente os de comunicação, para compor o sistema perceptivo-interativo do Design de Jogos ou game design. Isso necessita da projetação de um sistema de produtos, os quais interagem no desempenho do jogo. Observa-se que são atividades mais próximas da tradição do desenho industrial, porque visam a projetação de ilustrações, histórias em quadrinhos ou jogos de cartas entre outros produtos (BUSARELLO, 2016). 
A primeira abordagem é demonstrada na proposta de Yu-kai Chou (2015), que privilegia a relação entre gamificação e Design Comportamental. Sinteticamente, a proposta de Learn Gamification é representada no framework para gamificação Octalysis (Figura 1).

Figura 1- Octalysis da gamificação incrementado com funções pedagógicas.

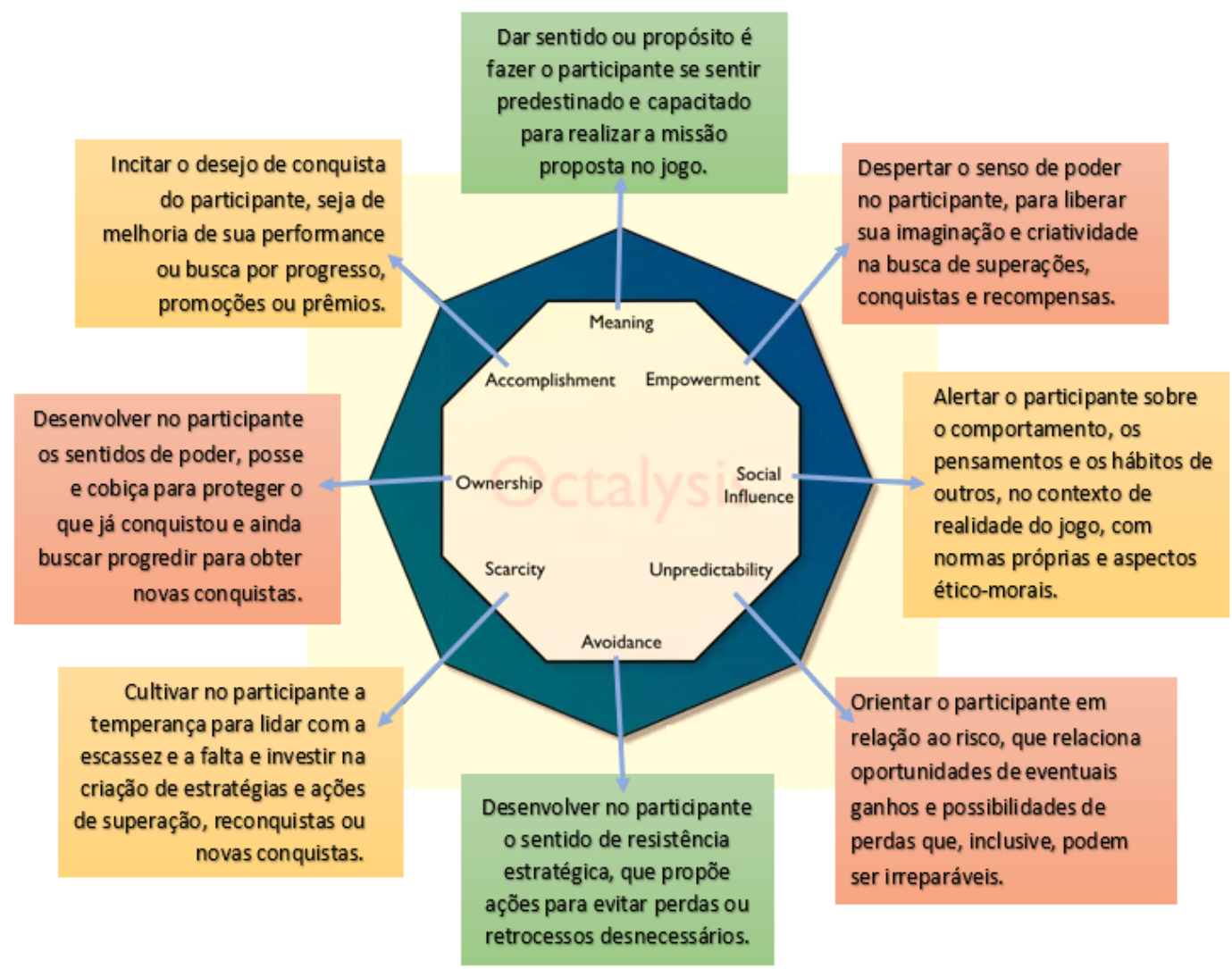

Fonte: Adaptado de https://yukaichou.com/

O desenho de octógono é usado para orientar a visualização de textos sobre premissas de gamificação. Em cada lado da figura é descrita uma motivação que deve ser contemplada na projetação de jogos e na gamificação. Conforme as interpretações das premissas são aqui propostas em função de seu potencial pedagógico-educacional (Figura 1):

- Meaning (sentido) indica a necessidade de se dar sentido ou propósito é fazer o participante se sentir predestinado e capacitado para realizar a missão proposta no jogo.

- Empowerment (empoderamento) propõe despertar o senso de poder no participante, para liberar sua imaginação e criatividade na busca de superações, conquistas e recompensas.

- Social influence (relações de contexto) alerta sobre a necessidade de o participante conhecer sobre o comportamento, os pensamentos e os hábitos de outros, no contexto de realidade do jogo, com normas próprias e aspectos ético-morais.

- Unpredictability (imprevisibilidade) requer que o participante seja orientado com relação aos riscos que proporcionam chances de ganhos e possibilidades de perdas que, inclusive, podem ser irreparáveis.

- Avoidance (precaução) indicando a necessidade de o participante desenvolver resistência estratégica e envidar ações que evitem perdas ou retrocessos desnecessários.

- Scarcity (lidar com a escassez) prevê a necessidade de temperança, para lidar com a escassez de recursos ou oportunidades, e investimentos em estratégias e ações de superação, reconquistas e novas conquistas. 
- Ownership (apropriação) assinala a introjeção dos sentidos de poder, posse e justo interesse pelo sucesso (cobiçar o êxito), seja para proteger o que já foi conquistado ou buscar novos êxitos.

- Accomplishment (conquista continuada) propõe o contínuo progresso do participante para melhoria de sua performance em busca de melhorias, promoções ou prêmios.

Observa-se a ênfase em questões subjetivas, intersubjetivas e comportamentais nos propósitos dessa primeira abordagem de gamificação que, mais especificamente, trata de aspectos pedagógicoeducativos. No contexto do planejamento e da prática didático-pedagógica, isso caracteriza a "educação em Design", assinalando a gamificação possível na projetação de processos, sistemas, serviços e produtos.

A outra abordagem reconhece a necessidade de produtos de uso ou comunicação para sinalizar, atuar na dinâmica e configurar sensorialmente a realidade do jogo. Por exemplo, isso requer a projetação e a produção de produtos gráficos (impressos ou digitais), como tabuleiros ou cenários e peças ou imagens de avatares, entre outros. O próprio Yu-kai Chou também propôs um jogo pedagógico Octalysis Prime (join.octalysisprime.com), como uma jornada de aprendizagem sobre gamificação, cujos cenários são compostos com ilustrações gráficas (Figura 2), audiovisuais e recursos interativos.

Figura 2- Tela de entrada Octalysis Prime- "A ilha é o centro de sua jornada".

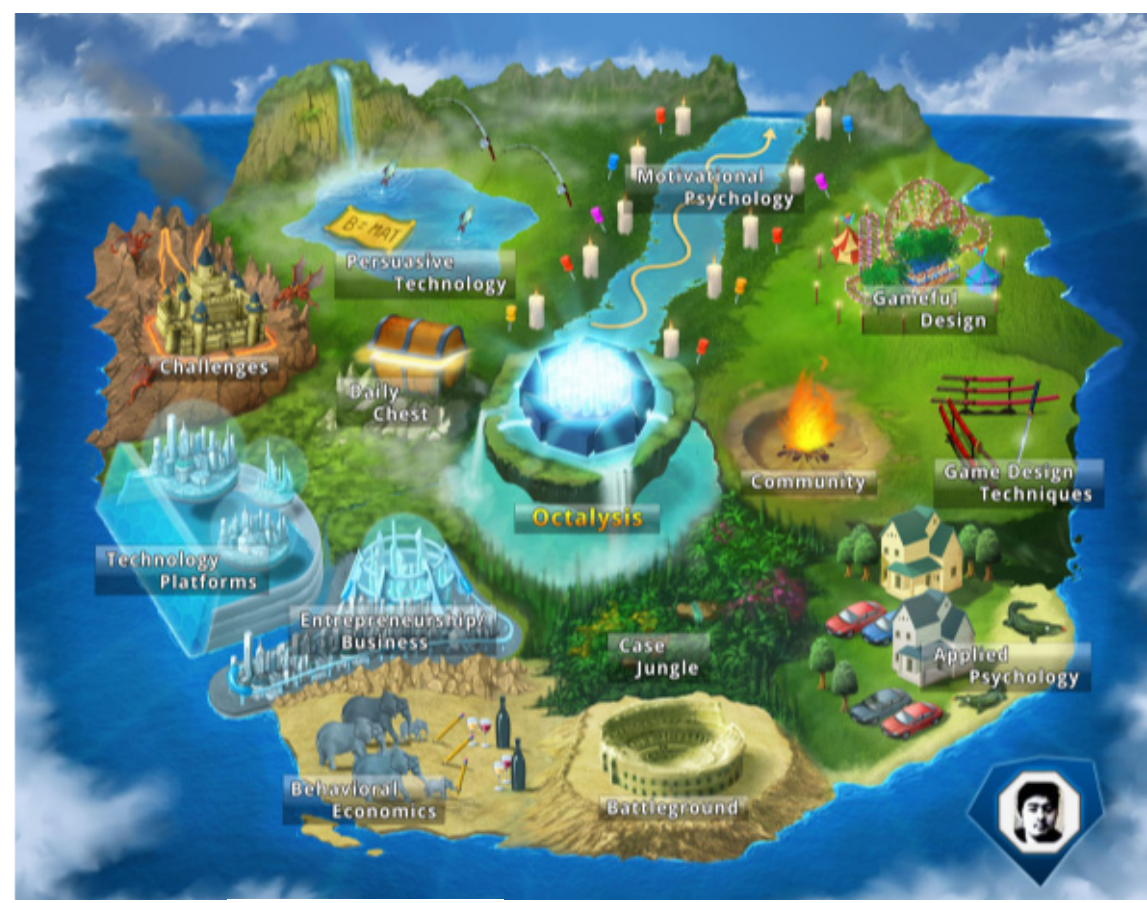

Fonte da imagem: join.octalysisprime.com/op-fr/

O aspecto de Design de Jogos (game design) que prioriza a produção de produtos foi beneficiada na era digital, seja com os recursos da computação gráfica, para informação, criação e divulgação de produtos de comunicação, ou devido à popularização do acesso, dos possíveis receptores ou interagentes, aos recursos tecnológico-digitais e às redes de comunicação online. Um exemplo e o acesso interativo-comunicativo ao jogo Octalysis Prime por pessoas de todo o mundo.

Por sua vez, Busarello (2016), no livro digital (e-book) Gamification, considera que os processos motivacionais e o divertimento nos processos de gamificação pedagógica ou educativa é incrementado e dinamizado por produtos de comunicação, ou seja, com "utilização e exploração de diferentes e criativas narrativas" (BUSARELLO, 2016, p. 08).

Pode-se considerar que a divulgação ampliada da ideia e das práticas de gamificação favorece e fortalece a área de Design. Isso porque a evolução de suas atividades tradicionais em constante interação com atividades e comportamentos humanos proporciona conhecimentos tácitos, explícitos, tecnologias e técnicas para destacá-la no desenvolvimento de jogos e nos projetos de gamificação. De certo modo, isso já foi consolidado na reunião formal de conhecimentos e práticas aplicadas na 
composição do recorte de Design de Jogos ou game design. Além disso, salienta-se neste artigo a positiva possibilidade de aplicação da gamificação na pedagogia-educativa e no processo de ensinoaprendizagem dos cursos de Design. Principalmente, porque os trabalhos de projetação ou o desenvolvimento de projetos já são organizados como um conjunto de desafios subsequentes e bem como dos procedimentos formais, precisam de uma dinâmica intuitivo-criativa.

\section{Considerações finais}

Há uma questão que emerge depois da afirmação de que os trabalhos de projetação ou o desenvolvimento dos projetos de Design são estruturais e de modo arrojado semelhantes aos jogos. Sendo que, isso pode ser resumido na seguinte pergunta: Qual a razão para indicar a gamificação como recurso didático-pedagógico nos cursos de Design se o desenvolvimento de projetos se assemelha aos jogos?

Primeiro é preciso considerar que, uma vez imersos no processo, os agentes envolvidos possam atuar sem dar a devida atenção para a estrutura, a dinâmica e a conjuntura processual. O bom senso indica que os peixes pouco percebem a água, em comparação com os animais terrestres ou alados. Da mesma maneira, os agentes humanos constantemente envolvidos deixam de investir ou podem não perceber a ludicidade em suas atividades. Por isso, ocorre aqui um alerta e uma proposta de recuperação e organização da ludicidade no processo didático-pedagógico em geral mais especificamente, nos cursos de Design.

Às vezes as necessidades e outras vezes os deveres acadêmicos ou profissionais sobrepujam o caráter lúdico ou o divertimento que as associa as atividades e os processos de Design ao jogo. Em muitas situações, o projeto de gamificação possui diferentes processos e atividades e solicita apenas basicamente a demarcação de elementos, aspectos e dinâmicas, para serem configurados como jogos (ULBRICHT; FADEL, 2014). Este fator aumenta as possibilidades criativo-inovadoras, por distanciar-se da proposição de modelos predefinidos.

Anteriormente, foi assinalada a necessária ruptura com o excesso de formalização e normalização, que era justificado em condições tecnológicas menos desenvolvidas. No apogeu da cultura industrial, a sociedade era dominada pela então revolucionária economia baseada na reprodução de processos e na fabricação seriada de produtos em grande escala (BONSIEPE, 1983).

As restrições tecnológicas que formalizavam a economia industrial foram automaticamente superadas. Inclusive, a superação do estritamente industrial pelo digital revolucionou os processos de produção. Por outro lado, alterou radicalmente a recepção e a comunicação de informações e produtos digitais, com o uso de aparatos tecnológicos (fixos e móveis) interligados às redes sociais online. Isso transformou fundamentos e parâmetros culturais, morais, sociopolíticos e pedagógicos.

Na composição diligente de processos e produtos de gamificação, foram aqui destacadas duas abordagens complementares, sendo uma baseada em Design Comportamental e a outra em Design de Produtos aplicado na configuração dos jogos. As duas abordagens caracterizam a especialidade de Design de Jogos ou game design. Assim, a proposta desafiadora descrita neste artigo é metalinguística, porque indica a aplicação de Design de Jogos nos processos didático-pedagógicos dos cursos de Design.

Em um primeiro momento, isso é indicado na proposta de reformulação do conhecimento e das práticas de projetação, integrando-os ao processo de gamificação. Basicamente, para tal demanda a reposicionamento estético-conceitual e organizacional de elementos, características e performances, para ressaltar sua natureza lúdica, de acordo com as premissas da gamificação. De igual forma sugerese a possibilidade da educação em Design e dos processos de ensino-aprendizagem por projetos.

Consequentemente, a educação por projetos pode e deve ser fundamentada na gamificação, incluindo também a criação de produtos gráfico-digitais ou audiovisuais de comunicação, na configuração da realidade sensorial do jogo didático-pedagógico. 
Gamification and Design Education in the Digital Age

Abstract: In general, gamification is the system of application of the structure and the playful dynamics of games in activities and processes. The orthodox conception of gambling indicates a voluntary activity, attributed to fun and with its own design. However, historically, part of the games was intend to serve other purposes. In this article, two complementary approaches are presented in the scope of Game Design, one pertinent to the field of Behavioral Design and the other closer to the Design and Communication Products, renewed with digital technology. The aim of this study is to indicate the application of gamification focused on pedagogical and educational aspects and on the particularities of teaching and learning in Design courses. The concepts and arguments presented here resulted from a qualitative research, carried out in two stages, one exploratory and the other bibliographic. As a result, the possibility of application of gamification in Design education and in the teaching-learning processes of courses in this area of knowledge becomes evident.

Keywords: Game Design; Pedagogical Gamification; Digital Culture

\section{Referências bibliográficas}

ANTOUN, H. O poder da comunicação e o jogo das parcerias na cibercultura. Revista Fronteiras Estudos Midiáticos. São Leopoldo, 2004.

BONSIEPE, G. A tecnologia da tecnologia. São Paulo: Edgard Blücher, 1983.

BUSARELLO, R. I. Gamification: princípios e estratégias. São Paulo: Pimenta Cultural, 2016. 126p.

CASTELLS, M. Redes de indignação e esperança. Rio de Janeiro: Zahar, 2013.

CHOU, Y.-k. Actionable Gamification: Beyond Points, Badges, and Leaderboards. Leanpub, 2015.

JENKIS, H. Cultura da Convergência. São Paulo: Aleph, 2009.

FARDO, M. A gamificação aplicada em ambientes de aprendizagem. RENOTE. Revista Novas Tecnologias na Educação, v. 11, p.1, 2013.

HUIZINGA, J. Homo ludens: o jogo como elemento da cultura. 5 ed. São Paulo: Perspectiva, 2007.

LÉVY, P. Cibercultura. São Paulo: 34, 1999.

MARCONI, M. A.; LAKATOS, E. Metodologia Científica. São Paulo: Atlas, 2007.

MATTAR, F. N. Pesquisa de marketing: metodologia, planejamento. São Paulo: Atlas, 2005.

MONTANARO, P.R. Gamificação para Educação. São Carlos: EdUFSCar, 2018.

PRENSKY, M. Digital natives, digital immigrants. On the Horizon. MCB University Press, v. 9, n. 5, out. 2001.

ULBRICHT, V.; FADEL, L. (Org.). Gamificação na educação. São Paulo: Pimenta Cultural, 2014.

VALENTIM, Marta L. P. Métodos qualitativos de pesquisa em ciência da informação. São Paulo: Polis, 2005.

WICK, R. Pedagogia da Bauhaus. São Paulo: Martins Fontes, 1989. 